\title{
A psicanálise no contexto da clínica escola
}

\section{Psychoanalysis in the context of the clinical school}

http://dx.doi.org/10.5007/2178-4582.2017v51n1p250

\author{
Cristina Adriana Rodrigues Kern e Aniely Kristine da Luz \\ Universidade do Extremo Sul Catarinense, Criciúma/SC, Brasil
}

\begin{abstract}
$\mathrm{O}$ estudo apresenta aspectos teóricos $\mathrm{e}$ práticos que envolvem o trabalho de estágio na clínica escola de um Curso de Psicologia em Santa Catarina, visando contribuir para discussões e reflexões críticas sobre esse universo. Tem por objetivo principal apresentar os fenômenos do campo do tratamento psicanalítico, abrangendo a sequência do trabalho da clínica com adultos, na particularidade da intervenção no contexto da clínica escola, por meio do diálogo entre a literatura e o relato de experiências da autora, acadêmica de Psicologia. Apresentam-se as vivências da autora ao longo do processo de construção do ser psicólogo e conceitos sobre dispositivos clínicos do âmbito da psicanálise que podem ser úteis ao público acadêmico em seu início de formação profissional. Conclui-se que a experiência da clínica escola é muito significativa, principalmente, por auxiliar na construção da identidade pessoal e profissional do estudante de psicologia.
\end{abstract}

Palavras-chave: clínica psicanalítica; clínica escola; formação.
The study presents theoretical and practical aspects involving the internship work in the school clinic of Psychology Course in Santa Catarina, in order to contribute to discussions and critical reflections on this universe. Its main objective is to present the phenomena of psychoanalytic treatment field, covering the sequence of clinical work with adults, particularly regarding intervention on the school clinic, through dialogue between literature and reporting experiences of the author. Some experiences are presented throughout the construction process of a psychologist that can be useful to the academic public in early training. It is concluded that the experience at the school clinic is very significant, mostly for being a defining moment in the building of personal and professional identity of a psychology student.

Keywords: psychoanalytic clinic; clinical school; training.

\section{Introdução}

As vivências ao longo do estágio de clínica possibilitam ao psicólogo em formação "sentir na pele" um pouco do que se imagina que Freud vivenciou em sua alquimia pessoal, desde os primórdios de seu trabalho, até o momento em que conseguiu transformar "metais em ouro". O mentor e sua obra passaram por transformações marcantes até que ele pudesse designar a Psicanálise como método investigativo, aquele que se caracteriza por buscar algo muito mais abrangente sobre o indivíduo, além daquilo que se manifesta em sua queixa. Assim, inicialmente buscou um tratamento para a doença de sua época e foi descobrindo uma forma de acessar o psiquismo, cujo legado propicia que continuemos essa alquimia, pesquisando e transformando, a partir dos elementos que fazem parte de nosso tempo. 
A partir do legado freudiano, esse trabalho apresenta os fenômenos que compõem o campo do tratamento psicanalítico no contexto da clínica escola, a partir de um diálogo entre a teoria e a experiência no estágio. Para tanto, contextualiza-se a Psicanálise e alguns conceitos enquanto recursos para o dispositivo clínico, apresentando a perspectiva de experiências no estágio; descreve-se a entrevista inicial enquanto um expediente para direcionar a sessão psicoterapêutica, relacionando à vivência do acadêmico; apresenta-se a importância da organização do setting terapêutico para o bom andamento do tratamento; demonstram-se aspectos do processo de diagnóstico e do processo terapêutico propriamente dito, integrados aos relatos da experiência da acadêmica ao longo de seu estágio clínico.

A inspiração de partida nessa trajetória foi o estudo da teoria Freudiana. Porém, o processo de construção da identidade de profissional psicólogo, requer apreender a teoria, supervisão sistemática e, como o próprio Freud referia, a escuta pessoal. Foi possível contar até então, com a dedicação aos estudos e com o suporte da supervisão, que por vezes perpassa a nós mesmos. Freud teve o grande desafio de escutar-se e escutar o outro, além de conceber uma teoria e uma técnica. O estudante tem o grande desafio de colocar em prática uma teoria e técnica que, muitas vezes, não vivenciou. Nesse sentido, o estudo e a supervisão devem ser profundos o suficiente para não deixar o acadêmico em um desamparo muito grande, pois basta o que já carrega por ainda não ter descoberto a si mesmo no processo psicanalítico. Freud enunciou a importância do tripé, contemplando a análise pessoal, a supervisão e o estudo teórico, fatores que sustentam atualmente a formação dos psicanalistas nas diferentes instituições (FREUD, 1919, p. 217-220). Contudo, de forma diversa às instituições de formação em psicanálise, na Universidade não se estabelece a escuta pessoal como um requisito, ficando a cargo de cada um essa escolha. Portanto, a princípio, o acadêmico se beneficia apenas com a assimilação da psicanálise através do estudo e da supervisão.

Freud (1912, p. 123-133) recomenda, ainda, que o movimento de escuta ao paciente aconteça de maneira aberta e livre de todo tipo de pré-concepções construídas em sua própria história, juntamente com a necessidade de não se prender às concepções teóricas ou ideais a respeito das formas de conduzir o destino pessoal. Assim, deve-se buscar manter uma abertura ao que pode emergir como algo novo e diferente, em cada relação em que se envolve. É importante ter em mente que, nesse ponto da construção da teoria, Freud já estava bastante "liberto de si mesmo". Sua liberdade foi construída aos poucos, na medida em que se abria diante de sua própria resistência e, ao mesmo tempo, se abria à atenção mais abrangente de seus pacientes, que acabaram por the ensinar o caminho para uma escuta mais acurada. Freud explorou "a si 
mesmo continuamente, e converteu-se no mais informativo de seus pacientes. Para seu trabalho ele não contava com predecessores nem mestres, e à medida que avançava teve de inventar, ele mesmo, as regras pertinentes" (SAIGH, 2007, p. 118). O próprio fundador "submeteu-se ao que só depois ele criaria. A psicanálise não existia antes de Freud: o primeiro psicanalista não teve, nem poderia ter tido, analista que o analisasse" (Id., 2007, p. 118). Uma forma de conhecer a síntese desse processo percorrido por Freud na construção da teoria, da técnica, bem como do processo autointerpretativo, é através do filme The Secret Passion. Trata-se de uma pseudo biografia de Freud que demonstra seu processo de autoanálise, baseada fundamentalmente na interpretação dos próprios sonhos, lembranças, lapsos, esquecimentos, bem como de sua resistência (PONTALIS, 1986).

A partir de uma perspectiva histórica, o método psicanalítico foi concebido ao longo de um complexo percurso e teve seu começo na compreensão da histeria, que é definida como um dos tipos de neurose e apresenta, essencialmente, duas formas sintomáticas: a histeria de conversão, cujo conflito psíquico simboliza-se em sintomas corporais diversos e a histeria de angústia, em que a angústia é fixada de modo mais ou menos estável em um objeto exterior (LAPLANCHE; PONTALIS, 1998).

Inicialmente, a hipnose e o procedimento catártico foram instrumentos para que o sujeito pudesse recordar eventos esquecidos, que estavam na base dos sintomas neuróticos. Com isso, as pacientes (predominantemente histéricas) conseguiriam liberar os afetos perturbadores relacionados a esses eventos (CONTE, 2004). No entanto, Freud (1903, p. 232-242) descobriu que as amnésias (esquecimentos) resultavam do recalcamento, um dos mecanismos de defesa do aparelho psíquico e que separa o desprazer da ideia correspondente, originando resistência "para que se reproduza a associação entre a ideia e esse afeto" (CONTE, 2004, p. 3). Nesse sentido, o psiquismo visa repelir ou manter no inconsciente as representações e, nessa operação, são produzidas "desfigurações que guardam relação com o desfigurado e que permitem que o material inconsciente torne-se consciente" (CONTE, 2004, p. 3). Em 1904, Freud escreveu um artigo, intitulado O método psicanalítico de Freud, onde descreveu as transformações de seu método, desde seus primeiros trabalhos com Breuer e esclareceu os inconvenientes do recurso à hipnose, visto que não destruía as resistências, fornecia informações parciais, e levava a sucessos provisórios (ROUDINESCO; PLON, 1998). Assim, constituiu o método da livre associação, que permitia atingir com maior facilidade os elementos que estavam em condições de liberar os afetos, as lembranças e as representações. Em decorrência, originou-se a regra fundamental, constitutiva da situação psicanalítica, segundo a qual o paciente é solicitado a dizer 
tudo o que lhe vier à cabeça, especialmente o que sentir tentado a omitir (ROUDINESCO; PLON, 1998).

A partir de suas experiências clínicas, Freud propôs a Psicanálise como um método de investigação sobre o significado inconsciente das palavras, das ações, dos sonhos, das fantasias, etc., fundamentado nas associações livres, as quais possibilitam validar a interpretação (LAPLANCHE; PONTALIS, 1992). Esse método de investigação fundamenta o método de tratamento, mantendo uma ligação de mútua utilidade prática e teórica (DUNKER, 2011).

A psicanálise foi conceituada, ainda, como um método psicoterápico baseado na investigação e na interpretação controlada da resistência, da transferência e do desejo. Por fim, outro conceito abarcado pela psicanálise refere-se à teoria psicológica e psicopatológica propriamente dita, "em que são sistematizados os dados introduzidos pelo método psicanalítico de investigação e de tratamento" (LAPLANCHE; PONTALIS, 1992, p. 385).

A abrangência do termo permite a ampla gama de possibilidades na clínica psicanalítica. Ocorreram modificações significativas que tiveram efeito na prática clínica nos trabalhos iniciais de Freud e autores pós-freudianos contribuíram com acréscimos e reorganizações, conforme as novas necessidades do ser humano, contextualizadas aos aspectos culturais (ZIMERMAN, 2004). Além das questões culturais, encontram-se as especificidades de atuação da clínica psicanalítica, como por exemplo, no contexto da clínica escola. A esse respeito, Birman (1994, p. 27) refere que a experiência psicanalítica aprova muitas possibilidades, "desde que nesta diversidade sejam reconhecidas as condições epistemológicas e éticas para a construção do espaço analítico", ou seja, "uma experiência centrada na fala, na escuta, e regulada pelo impacto da transferência". O autor ainda diz que a diversidade clínica se justifica não somente "pelas diferentes formas de funcionamento psíquico que se apresentam para a escuta analítica, mas também pela diversidade de espaços em que a experiência psicanalítica é possível" (BIRMAN, 1994, p. 27).

Portanto, graças à abrangência conceitual, é possível utilizar a teoria psicanalítica em outros espaços, além dos consultórios, tal como no contexto da clínica escola.

\section{Os fenômenos que compõem o campo do tratamento psicanalítico no contexto da clínica escola}

Algumas questões apresentam-se na clínica escola de forma comum à psicoterapia psicanalítica no consultório particular, porém, muitos aspectos divergem. A literatura propõe uma diferenciação entre psicanálise clássica 
e psicoterapia psicanalítica, ao considerar seus objetivos e, principalmente, as técnicas empregadas em seu processo terapêutico (EIZIRICK, 2005; KERNBERG, 2003; ZIMERMAN, 2004). Nessa perspectiva, a técnica diferencia o modo de intervenção, tendo em comum a teoria que abarca os conceitos de inconsciente, as pulsões, conflito, mecanismos de defesa, organização estrutural e topográfica do aparelho psíquico (EIZIRICK, 2005; KERNBERG, 2003; ZIMERMAN, 2004). Esses mesmos conceitos podem ser utilizados na clínica escola de psicologia, salientando-se que nesse contexto, também é a forma de intervenção que por vezes se altera.

A clínica escola é uma formação pela prática, dentro de um lugar onde se ensina - espaço de supervisão, discussão, construção do caso clínico e tratase de propiciar condições ao aluno para aprender com a vivência (MARCOS, 2011). Nessa direção, a experiência da acadêmica demonstrou que é preciso estar atento aos sentimentos despertados no início do trabalho de atendimento psicoterapêutico. O início dessa escuta traz uma grande expectativa ao estagiário, sendo de fundamental importância o modo de funcionamento de todo o contexto que envolve esse trabalho, desde a estrutura de funcionamento da clínica onde está sendo realizado o estágio, ao modo de acolhida do supervisor. Esse aspecto foi identificado também em uma pesquisa realizada na PUC de Minas Gerais, por meio de entrevista com quatro alunos que tiveram sua iniciação clínica feita no ambulatório do estágio de graduação do curso de Psicologia. Na pesquisa, a supervisão se configurou como lugar de "aprendizagem e de construção de um saber totalmente diferente da sala de aula, na medida em que a transferência com o supervisor foi apontada como um elemento fundamental para que o aluno não se sentisse intimidado por este profissional mais experiente e pudesse expor e conduzir o caso atendido" (MOREIRA, 2012, p. 867).

\section{Entrevista inicial}

No processo de formação na clínica escola, vivenciou-se a importância do primeiro contato, por uma série de fatores e que abrangem tanto o terapeuta quanto o paciente. Um deles, relativo ao paciente, foi que nesse início ele reúne as suas forças para chegar ao ponto da busca de auxílio e, grande parte dos pacientes, traz conteúdos muito importantes nesse momento. Nessa etapa, devem-se considerar as interrupções, a quantidade e qualidade da verbalização, o silêncio ou omissão sobre aquilo que o mesmo não quer expressar (KEIDANN; DAL ZOT, 2005).

Um dos aspectos dessa fase, comum ao consultório e à clínica escola refere-se à característica de que os pacientes, em grande parte, buscam o 
serviço porque sofrem e querem uma resposta para o seu adoecer e a clínica nos coloca diante da impossibilidade desta resposta, nessa modalidade imediatista. Há um "intervalo entre o pedido do paciente e a nossa resposta, não para superá-lo ou tamponá-lo, mas para apreendê-lo em sua existência constante, tal é o saber em jogo na clínica" (MARCOS, 2011, p. 207). Assim, dependerá das características do funcionamento do paciente para conseguir esperar a construção necessária para acessar essa resposta e, também, da habilidade do terapeuta para guiar esse caminho.

Nas entrevistas iniciais realizadas até então no estágio, chamou a atenção também a intensa necessidade de falar que vem sendo apresentada pela maioria dos pacientes, ansiedade ao expor a situação em cada detalhe e, muitas vezes, de forma acelerada, sendo preciso interromper e solicitar que pudessem repetir para tornar possível acompanhar e compreender determinada situação. Por outro lado, em alguns casos o silêncio se fez presente nos primeiros minutos da entrevista, durante o preenchimento dos dados necessários e, até mesmo quando, diante do silêncio, foi solicitado falar do motivo da busca por atendimento. $\mathrm{O}$ silêncio do paciente é um aspecto relevante de aprendizado nessa trajetória de construção técnica do terapeuta, pois tanto no início desse contato, quanto no transcorrer do tratamento, conseguir aguentar o silêncio, sem ter que se sentir na obrigação de preenchê-lo, é uma conquista bastante significativa. A esse respeito, salienta-se que os silêncios são parte da própria situação terapêutica, tendo sua função e sentido, tanto da parte do terapeuta, quanto do paciente e, relativos a esse último, podem ser citados: um bloqueio na sua capacidade para pensar; medo de decepcionar o terapeuta; forma de protesto, que acontece normalmente quando os anseios narcisistas do paciente não estão sendo gratificados; forma de controlar o terapeuta, uma forma de testar sua capacidade de continência, momento de associações livres em pensamento, as quais, por vezes, podem levar ao insight, entre tantas outras possibilidades (ZIMERMAN, 2004).

A forma como respondemos às falas ou aos silêncios dos pacientes, vai mostrando de que maneira funciona o espaço terapêutico e permite que se perceba o sentido dessa modalidade de escuta e intervenção. $O$ silêncio pode ter tantos significados, tantos quantos as palavras e, a habilidade de permitir a descoberta, é que faz toda a diferença. Em algumas situações, percebeu-se que a omissão da fala estava relacionada a não mexer na "ferida". A maneira que o paciente relata também requer especial atenção, ao tom de voz, ao nervosismo.

Esse começo de trabalho clínico nos remete a muitas dúvidas sobre como compreender o que está sendo apresentado a nós. Torna-se mais fácil quando conseguimos assimilar que não temos obrigação de dar conta naquela situação imediata, mas podemos aguardar para pensar melhor, supervisionar, estudar. 
Enfim, a evolução nesse sentido vai acontecendo junto com a experiência, e não antes. Quanto a esse aspecto, aparece novamente a supervisão como espaço com potencial considerável para o diálogo e a discussão/ transmissão das teorias que ajudam a configurar a experiência clínica, contribuindo para a construção de caminhos possíveis quando tudo parece obscuro demais (MEZZOMO, 2008). Os modos de indicação de psicoterapia são definidos pela entrevista inicial, não sendo uma entrevista separadamente, mas uma etapa em que o terapeuta vai apropriando-se dos sintomas do paciente, sobre a estrutura psíquica e, assim, observando qual a demanda de atendimento. Essa demanda abarca, entre outros aspectos, a avaliação em relação ao nível do desejo, a predisposição à associação livre e a capacidade do sujeito transferir. De acordo com Zimerman (1999, p. 285) hoje os casos contraindicados para a psicoterapia analítica são os casos de "degenerescência mental ou aqueles pacientes que não demonstram a capacidade mínima de abstração e simbolização, bem como aqueles que apresentam uma motivação esdrúxula, além de outras situações".

De acordo com o funcionamento da clínica escola, os acadêmicos têm esse contato inicial com os pacientes através de duas condições: na avaliação inicial onde, em continuidade, ocorrerá o acompanhamento psicoterapêutico e nas triagens. A triagem é definida como:

\begin{abstract}
[...] o primeiro atendimento prestado pelo profissional aos usuários dos serviços de saúde. Tem por finalidade a avaliação inicial, seleção e encaminhamento dos clientes às unidades/ especialidades adequadas à sua assistência. Entende-se que em qualquer lugar de uma instituição de saúde onde ocorre um contato entre trabalhador e usuário, existe a produção de um processo de trabalho em saúde por meio das relações de acolhimento, de vínculo, com forte conteúdo de intervenção terapêutica (AZEVEDO; BARBOSA, 2007, p. 33).
\end{abstract}

A triagem abrange uma entrevista inicial, porém de forma sucinta, pelo fato de que tem o propósito de coletar dados de identificação, verificar a urgência, verificar a carência e encaminhar para o atendimento clínico no serviço de psicologia e/ou para avaliação em outros serviços, tais como psiquiatria. O desafio dessa experiência é justamente manter o propósito dessa entrevista inicial sendo que, muitas vezes, nesse primeiro contato o paciente encontrase angustiado por diversos motivos, seja pela situação que está vivenciando, por expor seu problema a um desconhecido, ou por expor pela primeira vez suas dificuldades. Portanto, há uma particularidade ao ouvir e conduzir essa entrevista. Para tanto, deixa-se claro que não é uma consulta, mas uma triagem para coleta de dados e motivo de queixa. Além disso, fica claro que pode 
ser dado segmento ao trabalho junto ao mesmo estagiário ou não, sendo uma organização que tem a ver com disponibilidades de horários.

Este é um dos momentos marcantes no trabalho do estudante, onde se expõe pela primeira vez aos aspectos transferenciais e diante de sua contratransferência. Freud percebeu a dimensão da contratransferência, a qual definiu como "resultado da influência do doente sobre os sentimentos inconscientes", e referiu que "nenhum analista vai além do que os seus próprios complexos e resistências internas que lhe permitem", refletindo novamente a importância de o analista se submeter a uma análise pessoal, o que diminui as manifestações contratransferenciais, tornando a situação analítica estruturada e com uma superfície projetiva, apenas pela transferência do paciente (LAPLANCHE; PONTALIS, 1992, p. 102). A contratransferência é definida como "um conjunto das reações inconscientes do analista à pessoa do analisando e, mais particularmente, à transferência deste" (Id., 1992, p 102) e, considerando que em nossa profissão, o instrumento essencial de trabalho é o nosso psiquismo, a atenção aos sinalizadores apontados pela contratransferência é importante para conhecer melhor o outro, mas também para melhor dimensionar nossas condições particulares de atendimento para cada paciente.

Aqui vale ressaltar novamente a utilidade de uma visão imparcial, mediante o olhar do supervisor, o qual tem sob sua responsabilidade auxiliar o aluno a identificar em seu trabalho as facilidades e dificuldades acerca de vários aspectos, tanto teóricos quanto técnicos e, dentre esses aspectos, algumas dificuldades que podem ocorrer em nível da contratransferência do acadêmico com o(s) paciente(s). A partir disso, o supervisor tem a seu encargo pontuar tais questões para o aluno e este, por sua vez, se beneficiará se puder utilizar tais informações para trabalhar em um tratamento pessoal.

Além dos fatores apresentados, outra característica da entrevista inicial é que através dela se constrói uma razoável impressão diagnóstica do paciente, a qual serve como hipótese psicodinâmica e, conforme a necessidade pode ser feita a ampliação do diagnóstico clínico, utilizando manuais de transtorno mental (ZIMERMAN, 2004). Acerca do processo de diagnóstico, um contraponto entre o que acontece na clínica escola e o que ocorre na realidade do consultório, é que neste, o processo começa antes mesmo da primeira entrevista. Nos atendimentos em consultório particular, desde o telefonema do paciente já estamos obtendo informações a seu respeito. Já no trabalho em clínica escola, não temos essas informações, mas temos acesso a alguns dados que podem ser muito úteis antes do atendimento através da leitura da ficha técnica, quando o paciente já estava em atendimento. Na ficha é possível saber desde o motivo de busca, se houve encaminhamento, se foi por iniciativa 
própria, por pedido de familiar, etc. Todos esses dados nos fornecem pistas sobre sua motivação e diagnóstico (KEIDANN; DAL ZOT, 2005).

Um dos aprendizados que tem especial importância ao aluno em seus primeiros atendimentos com o paciente na clínica escola, é que se desobrigue de perguntar "qualquer pergunta" ou falar "qualquer coisa" mediante o que sente como certa "pressão". Por mais que tenhamos visto na teoria que o trabalho na psicoterapia de orientação psicanalítica propõe que deixemos o paciente livre para associar e, por nosso lado, realizemos a atenção flutuante, por vezes, fica difícil segurar nossa inquietação e deixar a entrevista seguir de forma mais livre. No momento em que nos conscientizamos realmente sobre o papel dessa forma de trabalho, torna-se muito mais fácil intervirmos nessa direção. Por exemplo, no caso de alguns pacientes que têm um funcionamento que os faz seguidamente perguntarem o que achamos do que ele está falando, ou apresentam silêncios frequentes ou demorados, ou referem "já disse tudo", o acadêmico, ciente da importância de compreender em profundidade o paciente, pode transmitir a ele a forma de funcionamento do espaço, especialmente nesses tempos inicias em que é necessário escutálos predominantemente, para poder avaliar e então saber sobre o que intervir. Este é um aspecto relevante, pois além de aliviar o aluno da "pressão", auxilia o paciente a compreender os modos de funcionamento do tratamento.

\section{Avaliação diagnóstica}

Um dos questionamentos que o acadêmico se faz nessa fase é sobre como funciona na prática a atenção flutuante. Freud criou a atenção flutuante para o terapeuta como um equivalente à regra fundamental do paciente. A regra da atenção flutuante abarca a ideia de que o terapeuta deve se abster à ânsia de compreensão do que ocorre com o paciente e trata- se de um processo ativo que deve contemplar uma sintonia afetiva e intuitiva (ZIMERMAN, 2004).

Outra dúvida comum ao acadêmico sobre o funcionamento da atenção flutuante se dá acerca do que investigar diante de tantas "informações". É importante investigar na avaliação psicodinâmica, a presença ou não de fatores desencadeantes, pelo fato de serem os responsáveis, na maioria das vezes, pela ruptura do equilíbrio anterior do indivíduo, onde a ausência desses fatores desencadeantes ou de crises vitais e acidentais pode ocorrer à hipótese de patologia de caráter (CORDIOLLI, 1998). Para avaliar a existência dos conflitos, Schestatsky (1989) introduziu os conceitos de conflito focal e nuclear, sendo formulações provindas do conceito freudiano de conflito psíquico. Os conflitos focais são derivativos de conflitos nucleares, profundos, primitivos, adormecidos, continuamente expressos no cotidiano e, portanto, 
mais próximos da superfície, pré-conscientes, explicando a maior parte do material clínico de uma sessão (KEIDANN; DAL ZOT, 2005).

Acerca dos pacientes com patologia de caráter estes possuem os referidos conflitos nucleares, infantis, que resultam em um modo habitual de ser, pensar, sentir, fantasiar, relacionar-se com os outros. Portanto, requerem um tratamento que se proponha a modificar, além do conflito atual, os conflitos infantis, sendo necessário retomar toda a história do paciente, lhe proporcionando melhores instrumentos e visando mudanças mais estáveis e profundas em sua vida (ETCHEGOYEN, 1990). Nessa direção, uma forma de abarcar essa proposta de tratamento em psicoterapia psicanalítica é através de uma frequência maior. Um exemplo da importância de um trabalho com maior frequência é se considerarmos a gravidade do tipo de angústia dos pacientes com transtorno de personalidade, tal como o borderline, em que prevalece angústia de aniquilamento e tende a estabelecer modos de relação primitivos, delegando grande importância ao outro na sua vida, por vezes de forma fusional. Assim, para que esse paciente possa reorganizar esses aspectos mais primitivos, torna-se fundamental oferecer um suporte de um tempo que comporte tamanhas mudanças internas.

Diante desse cenário, surgem muitas dúvidas sobre a verdadeira compreensão do fazer na prática clínica, onde se acredita, inicialmente, que iremos encontrar no referencial psicanalítico as respostas da teoria apenas transpostas para a prática e, ao vivenciar a clínica, enfrentamos um mundo diverso e, por vezes, controverso. Nesse sentido, um dos aspectos propostos para reflexão, pois não está de acordo com a técnica psicanalítica, é o que se direciona na instituição quanto à frequência, visto que na clínica-escola onde foi realizado o estágio, a frequência semanal é determinada de antemão, sendo apenas possível ampliá-la nos casos de risco de suicídio. De acordo com a teoria e técnica psicanalítica, a transferência, ampliada pela proximidade da frequência, é a mola propulsora do desenvolvimento e resolução do tratamento, sendo definida da seguinte forma:

Trata-se aqui de uma repetição de protótipos infantis vivida com um sentimento de atualidade acentuada. A transferência é classicamente reconhecida como o terreno em que se dá a problemática de um tratamento psicanalítico, pois são a sua instalação, as suas modalidades, a sua interpretação e a sua resolução que caracterizam este (LAPLANCHE; PONTALIS, 1992, p. 514).

O tratamento não cria, necessariamente, a transferência, mas "propicia a sua redescoberta, bastante facilitada pela instalação do setting, que 
favorece algum grau de regressão do paciente, por meio de uma intimidade" (ZIMERMAN, 2004, p. 134). Entende-se que, justamente, essa regressão que surge no tratamento e que se amplia mediante o aumento da transferência, propicia sua compreensão e, por conseguinte, sua resolução. Para resgatar, de alguma forma, o aspecto da restrição na frequência, foi proposta na supervisão a gravação dos atendimentos, com os devidos termos de consentimentos livre e esclarecidos assinados, para que pudesse ser explorado o atendimento de forma mais detalhada e, por consequência, abrangente. Esse recurso propicia a observação pormenorizada da associação livre (original) do paciente e, ao mesmo tempo, a detecção mais precisa da atenção flutuante que vem sendo realizada por parte do terapeuta. Assim, embora possamos visualizar a importância das redes de relacionamento que se constituem nos encontros do aprendiz com a teoria, com os professores, com a experiência de análise pessoal, não é possível desconsiderar o potencial alienante dessas relações, pois elas podem também se estabelecer a partir da adesão do pensamento do aprendiz ao suposto saber externo (MEZZOMO, 2008).

Nessa perspectiva, outro aspecto importante a levar em consideração para refletir, é a quantidade de pacientes que o acadêmico deve atender em seu período de estágio, pois se o número for muito alto, torna inviável que a supervisão se dê na forma de um relato dialogado do atendimento. Em uma hora de orientação semanal, a quantidade de pacientes faz toda a direção para pautar a qualidade de supervisão e, consequentemente, a qualidade do aprendizado do aluno.

Outro aspecto importante a investigar no processo de avaliação diagnóstica é acerca da relação temporal entre a eclosão dos sintomas e o acontecimento de algum evento ou circunstância na vida do paciente, relação frequentemente ignorada por ele devido a mecanismos de defesa protetores, como negação, racionalização, isolamento. Indicadores que podem direcionar a busca pelo conflito são, por exemplo, uma crise vital como, nascimento de filhos, adolescência, climatério, aposentadoria, ou crises acidentais, como perda por morte ou separação de um familiar, doença física própria ou de familiar, perda de emprego, casamento, vestibular, etc. (KEIDANN; DAL ZOT, 2005).

Outro tema que surge como ansiogênico ao estudante de psicologia e que, ao mesmo tempo, é um assunto significativo para a compreensão de seu trabalho clínico, refere-se aos modos de vínculo do paciente com o terapeuta. É crucial que o aluno tenha o conhecimento de que a forma do paciente se vincular, vai depender da qualidade das relações de objeto do passado, assim como de suas relações futuras (CORDIOLI, 1998). Essa compreensão por parte do aluno costuma propiciar que ele se liberte da angústia mediante as várias modalidades de transferência do paciente e, em particular, quando o 
paciente apresenta tamanha dificuldade em termos de vínculo, que não segue o acompanhamento. Assim sendo, diante do desconhecido e do aprendizado, o terapeuta "atravessado pela necessidade de precaver-se com a implicação do paciente com o tratamento, não encontrará facilmente respaldo em sua atitude" (MEZZOMO, 2008, p. 54).

Além de se apropriar das modalidades de transferência, as quais podem ter importantes repercussões sobre o aluno, seja por seu tom hostil ou pela via erótica, os modos de transferência também vão proporcionar dados muito úteis para entender o paciente. Nesse sentido, os padrões de relacionamento são sinalizadores da força global do ego, pois aqueles capazes de manter seus empregos ou vida acadêmica e também estabelecer relações de compromissos por períodos longos, provavelmente têm egos mais flexíveis e integrados, e ter um ego forte significa ter certo nível de inteligência, habilidade para tolerar emoções dolorosas, capacidade para sublimação e um teste de realidade bem estabelecido (CORDIOLLI, 1998).

\section{Setting terapêutico}

O setting abrange as regras e procedimentos que asseguram o bom desenvolvimento do processo e são estabelecidas desde os primeiros contatos. É o ambiente que se organiza a fim de propiciar as condições que favoreçam a instalação de um bom clima de trabalho (PECHANSKY, 2005). Assim sendo, tem a função de liberar ou impor limites ao funcionamento do atendimento terapêutico e do relacionamento entre a dupla. As regras podem ser discutidas durante o processo para que o trabalho possa acontecer com fluidez, embora haja algumas questões que são prerrogativas do terapeuta ou da instituição de atendimento. Além disso, a organização do setting não propõe um momento exato, uma sequência para as observações propostas sobre as regras técnicas (SILVA, 2013). Green (2008) propõe duas partes relativas ao setting terapêutico: os elementos que se referem à sua funcionalidade, tais como a arrumação do ambiente, uso do divã, as modalidades dos encontros, regularidades das sessões, seus cancelamentos e outras regulamentações e acontecimentos que podem advir entre o terapeuta e o paciente e, que concorram para o bom andamento do trabalho no desenvolvimento do processo psicanalítico.

$\mathrm{Na}$ experiência da clínica observada com pacientes pagantes, o setting é uma situação de difícil compreensão para os mesmos, pois não entendem o significado da quantidade de sessões, de pagar pelos atendimentos que não comparecerem e, no caso das análises, também o porquê se deve deitar no divã. Com o tempo, após o andamento das sessões, o paciente vai apropriandose de si e do sentido do processo psicanalítico e, aos poucos, temos a tarefa 
de auxiliá-lo a entender que um setting organizado contribui no seu processo terapêutico (SILVA, 2013). Na clínica escola, a acadêmica não passou por essa experiência, visto que os atendimentos são gratuitos, e também não teve que organizar a indicação de mais de uma vez por semana. Um fator relevante quanto ao atendimento psicoterapêutico, que trouxe insegurança no início do estágio, foi ter a responsabilidade de conduzir e organizar a sessão. O paciente, muitas vezes, fica com receios, retraído e quase sempre questiona onde deve sentar. Além disso, questiona como é o processo, sendo algo novo para ele e, por isso, causa certa ansiedade. Por essa razão, o acadêmico é quem tem a função de estar seguro de si e de como proceder diante das incertezas do paciente, agindo com cautela, pois na dúvida, sabe que poderá contar com a supervisão posteriormente. É importante delimitar um lugar para ambos, e observar a reação do paciente a partir do momento em que é direcionado a sentar-se em seu lugar. A organização e constância nesse aspecto podem parecer sem muito sentido ao acadêmico iniciante, mas com o tempo aprende as representações que isso pode ter.

Na clínica escola, alguns aspectos sobre o setting vão ao encontro dos aspectos apontados na literatura, outros divergem. Quanto ao atendimento, normalmente há uma constância sobre o horário e sala, os quais são determinados desde o primeiro atendimento. Quanto à estrutura física, a sala é ampla, a iluminação é padrão (não tendo a opção de adequá-la de acordo com a situação), bem ventilada e composta por: duas cadeiras com uma mesa e duas cadeiras estofadas próximas a uma poltrona (reclinável).

Na perspectiva da análise clássica, quanto à sua configuração em termos de estrutura física, o setting deve-se compor de, no mínimo um divã, uma poltrona, sala bem ventilada, pouca sonoridade e iluminação regulável, pois o analisando solicita mais ou menos claridade dependendo do estado de ansiedade, irritabilidade, angústia em que se encontra naquele momento (ZIMERMAN, 2004). A teoria psicanalítica propõe o uso do divã enquanto um instrumento que:

Tem funções específicas para o analista e analisando. Para o analista, sua função é libertá-lo da obrigação do olhar face a face diário com o analisando que desvia a concentração em seus próprios pensamentos e impede de dar todos os significados aos discursos do analisando em sua escuta, ora mais atenta, ora mais flutuante. Para o analisando, deitar-se no divã induz ao recolhimento que propicia o surgimento de lembranças, imagens, sentimentos, sensações e produção de fantasias. Passa de uma visão vertical, cheia de estímulos para uma visão onírica de sua vida interior, introspectiva, além de favorecer a regressão e a neurose de transferência (SILVA, 2013, p. 18). 
Na perspectiva das instituições de formação de analistas, o uso formal do divã indica que o trabalho realizado é a psicanálise clássica (análise). Essa formação pode ser feita nas instituições ligadas à International Psychoanalytical Association (IPA) ou outras instituições de psicanálise que oferecem cursos de formação. Quanto a esse aspecto, portanto, não estaria indicado o uso de divã em clínica escola.

\section{O processo terapêutico}

Para chegar a um determinado resultado, o processo de tratamento abrange alguns direcionamentos, principalmente, no início da busca pela psicoterapia, sendo um deles, o planejamento que não é estático, mas sim um esboço que serve como referência e que deve ser repensado ao longo do tempo (IANKILEVICH, 2005). Nesse sentido, um planejamento inicial cauteloso serve como marco, orientando a mente do terapeuta ao longo dos movimentos inevitáveis de seu trajeto. Como exemplo, entende-se que o planejamento pode ser necessário, nos momentos em que a regressão do paciente no campo tenda a acionar os aspectos narcisistas do terapeuta que se beneficiariam da necessidade que o paciente tem dele, correndo o risco de criar uma conspiração inconsciente para a manutenção da doença e da relação. Porém, não se pode esquecer que uma psicoterapia de bons resultados leva à alta, à separação, inevitáveis, mas nem por isso menos difíceis aspectos do crescimento (IANKILEVICH, 2005).

Muitos fenômenos transcorrem durante essa jornada, sempre embaraçada por forças inconscientes que tendem a manter o equilíbrio já existente, como enfatiza Freud (IANKILEVICH, 2005). No entanto, essas forças inconscientes não advêm apenas do paciente e, quanto a isso, mais uma vez vale ressaltar a importância da escuta pessoal para a eficácia do tratamento. O terapeuta se forma "fazendo da própria subjetividade objeto de investigação, sensibilizandose à escuta do inconsciente primeiramente em si mesmo, visando levantar os recalques que comprometem sua mobilidade psíquica". Assim, "sua capacidade de escuta decorrerá, principalmente, de seu desejo primeiro de se escutar e se fazer escutar" (NOGUEIRA FILHO; WARCHAVCHIK, 2008, p. 142). Por isso, “(o) fator individual sempre terá, na psicanálise, um papel maior do que em outras áreas" (FREUD, 1926, p. 220, apud NOGUEIRA FILHO; WARCHAVCHIK, 2008, p. 142).

O trajeto a ser percorrido é longo e complexo até que se atinja o objetivo inicial de ajudar o paciente a viver melhor, a não permanecer aprisionado ao problema que o fez buscar ajuda. 


\section{Considerações finais}

Parafraseando o título do trabalho "Alquimias vivenciais de adolescentes como aprendizes de si mesmos" (MACEDO, 1998, p. 1), esse estudo apresentou as alquimias ${ }^{1}$ vivenciais ao longo do estágio de clínica, significativas no processo de construção de ser psicólogo. Para tanto, apresentaram-se os diversos fenômenos que compõem o campo do tratamento psicanalítico no contexto da clínica escola, contextualizando a Psicanálise, seus conceitos e técnica, enquanto recursos para o dispositivo clínico. Apresentou-se também a perspectiva da experiência da autora (acadêmica) no estágio de Psicologia clínica, bem como se revisaram estudos realizados nesse contexto da clínica escola.

O que motivou o início da autora à trajetória de se tornar psicóloga, foi o interesse por recursos humanos (RH). Desde o começo do curso ao momento atual, a empresa perdeu lugar dentro da acadêmica e a clínica ganhou espaço. Inicialmente, a clínica era vista como difícil e, até mesmo, assustadora, pela lógica da imensa responsabilidade diante do que fazer acerca do outro.

No decurso do caminho acadêmico, a absorção de teorias e as vivências possibilitaram, de certa forma, um pouco mais de tranquilidade para o atendimento psicológico. Contudo, o encantamento surgiu apenas no momento da prática e o prazer não esteve só, mas acompanhado da angústia sobre o desconhecido. Uma das maiores questões circundava acerca de como saber sobre o outro, sendo que ele próprio não sabe? Esse parece ser um dos paradoxos fundamentais que sustentam o trabalho mediante a clínica psicanalítica: a resposta para as dificuldades está dentro de nós, seja terapeuta ou paciente, mas é preciso dar abertura para uma escuta profunda e genuína, acompanhada de paciência.

Ao longo desse trabalho artesanal, buscou - se apresentar algumas práticas ao longo do estágio, consideradas significativas no processo de construção do ser psicólogo. Pode-se dizer que a conclusão essencial acerca desse trabalho, vai ao encontro do que propõe Silva (2013, p. 3) de que trabalhar com a Psicanálise envolve dois tempos:

O primeiro é mais fácil, que é a apreensão da teoria e o segundo, é o momento da prática clínica que demanda muito tempo, esforço e exige qualidades especiais do terapeuta, visto que é o momento de lidar com as imprevisibilidades, quando se depara frente a frente com o paciente, cada um com sua carga psíquica e ambos preenchidos pela força de seus desejos.

1 Alquimia remete, além da ideia da transformação de metais em ouro, à metáfora de mudança de consciência (FERREIRA, 2005). 
Outro aspecto observado tanto na teoria quanto na prática, foi que a clínica é um lugar de pesquisa e de reflexão e também um ponto de interseção da universidade com a comunidade. Isso significa que a universidade não é autônoma, pois ela existe na relação com a comunidade e com a sociedade. Assim sendo, a clínica-escola não é voltada apenas para a formação do aluno, pois dessa forma seria determinada pelo processo acadêmico. Também "não é o processo de ensino que determina a clínica, mas a atenção à saúde e o cuidado com o sofrimento psíquico. $\mathrm{O}$ atendimento à comunidade é, neste sentido, formador" (MARCOS, 2011, p. 206).

Nessa perspectiva, no transcorrer desse percurso surgiram alguns questionamentos decorrentes de algumas diferenças consideradas importantes entre aquilo que estudamos e o que vivenciamos no trabalho na clínica escola. Mesmo nesses impasses, buscaram-se alternativas para que, mesmo frente à necessidade de certa diferenciação técnica em psicanálise, houvesse um cuidado maior por outra via, como por exemplo, na medida em que se garantiu o acompanhamento das associações livres de alguns pacientes em sua forma original. Contudo, essa é uma das questões que se apresenta ainda como alvo de discussão e requer a continuidade de reflexões a respeito.

Portanto, dentre os aspectos envolvidos na formação do terapeuta, cabe ressaltar a forma de relação proposta pela instituição ao aprendiz:

\footnotetext{
Por um lado, o papel da instituição nesse contexto é determinante, seja fornecendo sustentação para a construção de questionamentos contínuos a respeito da prática clínica, seja como fonte de transmissão dos saberes necessários para a realização do ofício (MEZZOMO, 2008, p. 17).
}

Assim sendo, o tipo de vínculo do formando com a instituição também é fundamental determinante na construção profissional e pessoal do aprendiz, podendo induzir à reprodução das relações de poder e à homogeneização das subjetividades (MEZZOMO, 2008). Por isso, a necessidade de ter criticismo diante da vida, seja frente a uma instituição, teoria, ou qualquer realidade que se coloque como verdade absoluta.

Um momento que, efetivamente, é gratificante nesse processo é quando conseguimos a tranquilidade de acolher a experiência tal como se dá a cada indivíduo e podemos experimentar acompanhá-los na desconstrução de antigos sentidos e a reconstrução de novos significados para suas vivências (FIGUEIREDO, 1996). Pode-se dizer que foi possível experimentar minhas próprias alquimias vivenciais nesse processo de construção do ser psicólogo. Contudo, ao longo desse transcurso percebe-se que nosso fazer se defronta 
com uma série de situações que nos põe diante da potencialidade de mudanças, mas elas só acontecem se permitirmos sermos aprendizes de nós mesmos. É importante, se realmente quisermos atuar de forma consistente nessa área, nos colocarmos abertos a essas propostas de reorganizações que esse trabalho nos convida.

Conclui-se, finalmente, que desses cinco anos de formação profissional, o último, o qual comporta o espaço percorrido na clínica escola é o mais significativo, por todo aprendizado teórico e prático proporcionado e, fundamentalmente, por ser um momento marcante na construção da identidade pessoal e profissional do estudante de psicologia.

\section{Referências}

AZEVEDO, J. M. R.; BARBOSA, M. A. Triagem em serviços de saúde: percepções dos usuários. Revista de Enfermagem, UERJ, Rio de Janeiro, v. 15, n. 1, p. 33-39, jan./mar., 2007. Disponível em: $<$ http://www.facenf.uerj.br/v15n1/v15n1a05.pdf $>$. Acesso em: 05 out. 2014.

BIRMAN, J. A direção da pesquisa psicanalítica. In: Psicanálise, ciência e cultura. Rio de Janeiro: Jorge Zahar, 1994. p. 13-27.

CONTE, B. de S. Reflexões sobre o método e a metodologia em Psicanálise. Revista da Sociedade de Psicologia do Rio Grande do Sul, Porto Alegre, v. 1, n. 3, p. 06-10, jun. 2004.

CORDIOLLI, A. V. Psicoterapias: abordagens atuais. 2. ed. Porto Alegre: Artmed, 1998.

DUNKER, C. Estrutura e constituição da clínica psicanalítica: uma arqueologia das práticas de cura, psicoterapia e tratamento. São Paulo: Annablume, 2011.

EIZIRICK, C. Psicoterapia de Orientação Analítica. Porto Alegre, Artmed, 2005.

ETCHEGOYEN, R. H. Psicanálise e psicoterapia de orientação analítica; semelhanças e diferenças. Revista de Psiquiatria do Rio Grande do Sul, v. 12, n. 3, p. 209-213, set./dez.1990.

FERREIRA, A. B. de H. Miniarélio: o dicionário da língua portuguesa/ Aurélio Buarque de Holanda Ferreira; coordenação de edição Margarida dos Anjos, Marina

Baird Ferreira. 6. ed. rev. atual - Curitiba: Positivo, 2005.

FIGUEIREDO, L. C. Revisitando as psicologias: da epistemologia à ética das práticas e discursos psicológicos. São Paulo: Educ; Petrópolis: Vozes, 1996.

FREUD, S. El método psicoanalítico de Freud. In: Edição Standard Brasileira das Obras Completas de Sigmund Freud, v. 7, p. 232-242. Buenos Aires: Amorrortu, 1990. (Original publicado em 1904). 
FREUD, S. Recomendações aos médicos que exercem a psicanálise. In: Edição Standard Brasileira das Obras Completas de Sigmund Freud, v. 12, p. 123-133, Rio de Janeiro: Imago, 1996. (Original publicado em 1912).

FREUD, S. Sobre o ensino da psicanálise nas universidades. In: Edição Standard Brasileira das Obras Completas de Sigmund Freud (Tradução J. Salomão, v. 17, p. 217- 220). Rio de Janeiro: Imago. 1976. (Original publicado em 1919).

GREEN, A. Orientações para uma psicanálise contemporânea. Rio de Janeiro: Imago, 2008.

GREENSON, R. R. A técnica da psicanálise. Rio de Janeiro: Imago, 1981.

IANKILEVICH, E. Planejamento. In: EIZIRICK, C; AGUIAR, R; SCHESTATSKY, S. (Orgs.) Psicoterapia de orientação analítica: fundamentos teóricos e clínicos. 2. ed. Porto Alegre: Artmed, 2005. p. 207-217.

KEIDANN. C. E.; DAL ZOT, J. S. Avaliação. In: EIZIRICK, C; AGUIAR, R.; SCHESTATSKY, S. (Orgs.). Psicoterapia de orientação analítica: fundamentos teóricos e clínicos. 2. ed. Porto Alegre: Artmed, 2005. p. 177-193.

KERNBERG, O. Psicanálise, psicoterapia psicanalítica e psicoterapia de apoio: controvérsias contemporâneas. In: GREEN, A. (Org.). Psicanálise Contemporânea. São Paulo: Imago; 2003. p. 23-50.

LAPLANCHE, J.; PONTALIS, J. Vocabulário da Psicanálise. São Paulo: Martins Fontes, 1992.

MARCOS, C. M. Reflexões sobre a clínica-escola, a psicanálise e sua transmissão. Psicologia Clínica, Rio de Janeiro, v. 23, n. 2, 2011, p. 205-220. ISSN 0103-5665. Disponível em: <http:// dx.doi.org/10.1590/S0103-56652011000200013 > . Acesso em: 23 set. 2014.

MACEDO, M. M. K. Alquimias vivenciais de adolescentes como aprendizes de si mesmos. 1998. 190f. (Mestrado em Educação) - Curso de Pós-Graduação em Educação, Pontifícia Universidade Católica do Rio Grande do Sul, Porto alegre.

MEZZOMO, L. Aprendendo a fazer psicanálise: dificuldades e conflitos de uma psicoterapeuta no início de suas atividades clínicas. Disponível em: <http:/www.dominiopublico.gov.br/ download/texto/cp056108.pdf>. Acesso em: 12 ago. 2014.

MOREIRA, M. C. A supervisão em Psicanálise na Clínica Escola: breve relato de uma pesquisa. Revista Mal-estar e Subjetividade, Fortaleza, v. XII, n. 3-4, set./dez., 2012, p. 853-872. Disponível em: $<\underline{\text { http: } / / w w w . r e d a l y c . o r g / p d f / 271 / 27130172015 . p d f ~}>$. Acesso em: 13 out. 2014.

NOGUEIRA FILHO, D. M; WARCHAVCHIK, V. L. H.. Formação do analista: um impasse necessário. Jornal de psicanálise. São Paulo, v. 41, n. 74, p. 141-150, jun. 2008. Disponível em $<$ http://pepsic.bvsalud.org/scielo.php?script=sci_arttext\&pid=S0103-58352008000100009\&ln $\mathrm{g}=\mathrm{pt \& nrm}=$ iso $>$. Acesso em 26 abr. 2016.

PECHANSKY, I. Setting psicoterápico: neutralidade, abstinência e anonimato. In: EIZIRICK, C.; AGUIAR, R.; SCHESTATSKY, S. (Orgs.) Psicoterapia de orientação analítica: fundamentos teóricos e clínicos. 2. ed. Porto Alegre: Artmed, 2005. p. 234 -245. 
PONTALIS, J. B. Prefácio. In: SARTRE, J-P., Freud Além da Alma: roteiro para um filme. Rio de Janeiro: Nova Fronteira,1986, p. 07-25.

ROUDINESCO, E.; PLON, M. Dicionário de Psicanálise. Rio de Janeiro: Jorge Zahar, 1998.

SAIGH, Y. A. A auto-análise 150 anos depois de Freud. Psyche, São Paulo, v. 11, n. 20, p. 117128, jun. 2007.

SCHESTATSKY, S. Introdução ao planejamento em psicoterapia. In: EIZIRICK, C.;AGUIAR, R.; SCHESTATSKY, S. Psicoterapia de Orientação Analítica: teoria e prática. Porto Alegre: Artmed, 1989. p. 71-78.

SILVA, D. C, da. Curso de especialização em teoria psicanalítica. 2011-2013. Brasília, 2013. Disponível em: http://bdm.unb.br/bitstream/10483/5447/1/2013 DeleciaCandidadaSilva.pdf. Acesso em: 12 de agosto de 2014.

ZIMERMAN, D. E. Fundamentos psicanalíticos: teoria e clínica - uma abordagem didática. Porto Alegre: Artmed, 1999.

ZIMERMAN, D. E. Manual de Técnica Psicanalítica: uma revisão. Porto Alegre: Artmed, 2004.

Submissão em: 05/12/2014

Revisão em: 07/08/2016

Aceite em: 31/10/2016

Cristina Kern é professora da Universidade Estadual do Extremo Sul Catarinense. Endereço: Rua Bortolo Pavan, 352. Apto. 702, Bairro Santa Augusta. Criciúma/SC, Brasil. CEP 88805-245. E-mail: cristinakern04@yahoo.com.br

Aniely Kristyne é psicóloga formada pela Universidade Estadual do Extremo Sul Catarinense.

E-mail: anielykristyne@hotmail.com 